\title{
Discussão Acerca do Significado do Termo “Design" Utilizado em Produtos e Serviços
}

\author{
Discussion About the Interpretation of the Term "Design" Used in Products and \\ Services
}

ARRUDA FILHO, Moisaniel Pimentel; Graduando em Design; UFMA moisa_filho@hotmail.com

BARROS, Rubenio dos Santos; Mestrando em Design; UFSC

rubeniobarros@hotmail.com

DINIZ, Raimundo Lopes; Programa de Pós-Graduação em Design; UFMA

rl.diniz@ufma.br

\section{Resumo}

O presente artigo busca investigar a relação de uso e interpretação do termo "design", bem como qual a disseminação do termo de forma plural quando utilizado no oferecimento de produtos e serviços. Para tal, utilizou-se uma abordagem qualitativa com objetivo descritivo, apresentando como procedimento técnico a aplicação de um questionário a estudantes e profissionais da área de Design e, ainda, a pessoas que não são da área. Os resultados sugerem que o uso da palavra design está amplamente associado com a dimensão estética ou na utilização como um "adjetivo" de qualidade em seus serviços, sendo que a profissão Design é compreendida como uma vantagem competitiva no comércio.

Palavras Chave: design, significado, produtos e serviços.

\begin{abstract}
This paper seeks to investigate the use relation and interpretation of the term "design", as well as how the term is spread in a plural form when applied in the advertisement of products and services. For that, a qualitative approach with descriptive objective was performed, involving as technical procedure the application of a questionnaire among Design students and professionals, and also to other people who are not from Design area. The results suggest that the use of the word design is widely associated with the aesthetics dimension or used as an "adjective" of quality in services, and Design is seen as a competitive advantage in commerce.
\end{abstract}

Keywords: design, meaning, products and services.

\footnotetext{
${ }^{1}$ A apresentação deste artigo no evento foi financiada pelo edital Participação em apoio científico da FAPEMA
} 


\section{INTRODUÇÃO}

O design no mundo atual desdobra-se com maior relevância desde a sua explosão nas mídias durante a revolução tecnológica, chegando com mais facilidade ao conhecimento da população. Contudo, ele ainda não é bem difundido e a dificuldade de seu entendimento por completo é facilmente notada. Não é raro perceber o seu emprego em áreas como hair design, cake design ou designer de sobrancelhas, aplicações que definitivamente levantam discussões constantes acerca de sua validade. Niemeyer (1997) apud Moura (2003) aponta que estes casos eram empregados em situações mais requintadas, mas que atualmente são vistos em salões simples e populares.

Devido ao caráter multidisciplinar, o design é capaz de alcançar todas as esferas da sociedade. Desta forma, o contato com o termo "design" ocorre constantemente, fazendo parte de um novo vocabulário (AZEVEDO, 1998). Landim (2010) relata que o termo passou a ser bastante explorado pelos meios de comunicação para agregar valor à imagem, mas o desconhecimento ao conteúdo intrínseco do design gera usos deturpados em alguns ramos de negócios.

De acordo com Moura (2003), no Brasil, o termo "design" teve origem nos anos 50 com o curso de desenho industrial e, somente a partir dos anos 80, a utilização da nomenclatura em inglês a qual hoje conhecemos foi aplicada. Entretanto, pelas palavras de Diniz et al. (2016, p. 804) "os profissionais, pesquisadores e estudiosos da área almejam ainda por definir de forma sólida o que é o design, pois os seus significados têm implicado na massificação do termo e utilizações impróprias da palavra".

Bomfim (2014) relata o desencorajamento para a formulação de uma teoria concreta e sólida para o design diante das problemáticas referentes ao seu desenvolvimento, pois em suas análises, destacou-se a instabilidade do campo, pois o mesmo admite a falta de conhecimentos fixos em suas disciplinas, já que os temas, ações e problemas tratados neste domínio são amplos e vão ao encontro de outras áreas, o que também o caracteriza como transdisciplinar. Em outras palavras, a sua complexidade, instabilidade em seu corpo de conhecimento e a sua transdisciplinaridade cooperam para os problemas ressaltados. Além disso, o design também se defronta, no contexto brasileiro, como um campo sem regulamentação, relativamente novo e com a sua denominação alterada nos anos 80 , dessa forma, a má disseminação e interpretação do design acabam sendo consequências (MOURA, 2003).

Visto isso, o presente artigo busca investigar mais a fundo a relação de uso e significado do termo "design" em produtos e serviços, entre profissionais e estudantes da área, além de outras pessoas que não são da área. Em suma, o objetivo é compreender a aplicação do termo, os fatores contribuintes de sua disseminação e interpretação e, ainda, a utilização do termo de forma plural em produtos e serviços.

\section{A PLURALIDADE DO TERMO “DESIGN”}

Primeiramente, deve-se ter em mente que o termo design nasceu recentemente, junto à revolução industrial, no século XVII, na Inglaterra. Foi neste contexto pré-estabelecido que o design começa a caracterizar uma atividade profissional, específica àqueles que configuram objetos de uso e sistemas de informação (BOMFIM, 2002). A partir desse momento histórico e ao longo das revoluções vivenciadas pela sociedade, o design amplifica os seus limites e, assim, 
amadurece, evolui e reforça o seu caráter pluralista e interdisciplinar, compreendendo uma extensa dimensão quanto à constituição de sua essência.

Diniz et al. (2016) discorrem sobre a polissemia apresentada na área, em que é possível observar todos esses aspectos presentes no design. De acordo com os seus estudos e a categorização do design formulada por Possatti, Linden e Silva (2014), o termo "design" por si só abarca múltiplas definições (design como aparência do produto, verbo, artefato, representação, etc.). Além disso, o termo ganhou novas atribuições à medida que o mercado ditava novas demandas, assim como manifestavam-se novas tecnologias, como visto recentemente na área digital ou na área da informação e gerenciamento de design.

Ainda, de maneira geral, a disseminação atual do termo nem sempre é clara, como Löbach (2001) exemplifica ao delatar as suas diversas definições encontradas nos dicionários, como, por exemplos: projeto, plano, esboço, desenho, croqui, construção, configuração e modelo.

Para alguns teóricos da área, como apresentado e determinado por Bonfim (2014), é possível estabelecer, por meio de uma análise comparativa entre as definições pré-existentes, que o design trata-se de uma atividade que objetiva a configuração de objetos de uso e sistemas de informação. Em termos de configuração, significa processo ou projeto (configurar), contudo, também se relaciona com as significâncias atribuídas a forma. Löbach (2001) corrobora com este caráter configurativo, explanando que o conceito pode ser descrito e ampliado como o processo de materialização de uma ideia.

Além disso, ainda vale apresentar a apropriação do design pelas indústrias e pela mídia, estes que representam apenas aspectos parciais de produtos e/ou serviços, como por exemplo e mais comumente recorrente, o forte apelo estético em virtude de divulgação, venda e lucro (MOURA, 2003). Através disso, gerou-se a utilização equivocada do design em qualquer segmento comercial, passando a ser compreendido como "valor estético" e "agregador de valor" pela sociedade como um todo, o que ocasiona a proliferação do design da forma como é conhecido popularmente nos meios urbanos.

\section{POSSIBILIDADES DE INTERPRETAÇÃO DO TERMO “DESIGN” NO BRASIL}

Cardoso (2013) explana que o design se torna mais complexo à medida que o mundo se desenvolve, aumentando, por conseguinte, o número de inter-relações entre as suas partes, o que contribui para as dificuldades de interpretação da sua posição e atuação, gerando dúvidas quanto ao papel do design com relação a outras áreas profissionais. Fascioni (2014) exemplifica essa questão quando discute sobre a atuação do design e da publicidade apontando que as mesmas são áreas complementares, mas que sua diferenciação reside no uso de abordagens completamente diferentes.

Ainda que esta abrangência de conhecimentos cause um certo desentendimento da interpretação do termo design no território brasileiro, existem outros motivos que podem explicar ou então reforçar a existência dessas possíveis dificuldades de entendimento deste. Moura (2003), por exemplo, expõe três motivos que justificam essa falta de entendimento: na primeira instância, em termos históricos a profissão do designer é um campo relativamente recente no Brasil, tendo origem na década de 50, o que acaba por não consolidar o seu campo de conhecimento; em segundo, a profissão do designer no país não é regulamentada; o terceiro e último, expõe-se que a mudança na nomenclatura de desenho industrial, como era previamente aplicada até meados dos 
anos 80, para o termo em inglês "design" ocasionou uma confusão em suas interpretações. Além disso, este passou a desempenhar um papel muito mais eminente, abrangendo áreas que vão além do desenho industrial (MOURA, 2003).

Os autores Löbach (2001), Bonsiepe (2012) e Landim (2008), apontam outros fatos que contribuem para a formação de conceitos errôneos sobre o design, como a ampla exposição disseminada pela publicidade nas últimas décadas, que acabou gerando um conhecimento superficial do que é o design para a sociedade, e ainda destacam que o seu conceito é amplamente relacionado à beleza e às configurações estéticas, não incluindo, assim, o seu processo projetual como um todo. Frente a isso, deve ser destacada a importância da comunicação, pois como afirma Moreira (2016, p. 74), "a comunicação se concretiza como um elo em meio aos processos relativos à prática do Design, em virtude de aquela reunir áreas e, portanto, competências inerentes a diferentes campos do conhecimento". A autora complementa ainda que o déficit de conhecimento pode tornar a prática do designer subutilizada, acarretando uma construção equivocada do modelo mental acerca de sua amplitude de funções, além de gerir o Design apenas no âmbito operacional (MOREIRA, 2016).

Nos dias atuais ainda se discute o conceito de design, e é possível observar a presença do tema em congressos da área em uma tentativa de definir um escopo teórico para o campo. Possatti, Linden e Silva (2014), por exemplo, expuseram a gama de vertentes que o termo design abrange, propondo uma classificação para a palavra dentro de sua complexidade e polissemia, como visto no Quadro 1 abaixo.

Quadro 1: Classificação da palavra design por Possatti, Linden e Silva (2014).

\begin{tabular}{|c|c|c|c|c|}
\hline $\begin{array}{l}\text { Substantivo } \\
\text { abstrato }\end{array}$ & Verbo & Representação & Artefato & $\begin{array}{l}\text { Resolução de } \\
\text { problemas }\end{array}$ \\
\hline $\begin{array}{l}\text { Tem alusão a } \\
\text { plano, desígnio e } \\
\text { intenção, na qual } \\
\text { expressa projeto } \\
\text { no sentido de } \\
\text { desejo ou a ideia } \\
\text { de produzir ou } \\
\text { realizar algo. }\end{array}$ & $\begin{array}{l}\text { Significa desenhar, } \\
\text { indicar, designar, } \\
\text { simular, dispor, } \\
\text { representar, dar } \\
\text { forma, ordenar, etc. É } \\
\text { um conjunto de ações } \\
\text { que resultam em um } \\
\text { produto final. }\end{array}$ & $\begin{array}{l}\text { Esboço, desenho, projeto, } \\
\text { um modelo de } \\
\text { representação gráfica. } \\
\text { Consiste na forma de } \\
\text { transpor a ideia (o } \\
\text { imaterial, abstrato) ao } \\
\text { concreto, transformando- } \\
\text { o em artefato. }\end{array}$ & $\begin{array}{l}\text { É o próprio } \\
\text { produto da } \\
\text { concepção de um } \\
\text { projeto e o } \\
\text { resultado pode } \\
\text { ser tanto } \\
\text { bidimensional } \\
\text { como } \\
\text { tridimensional. }\end{array}$ & $\begin{array}{l}\text { É a forma como } \\
\text { o designer utiliza } \\
\text { métodos e } \\
\text { técnicas para } \\
\text { atingir } \\
\text { determinados } \\
\text { objetivos. }\end{array}$ \\
\hline $\begin{array}{l}\text { Aparência de um } \\
\text { produto }\end{array}$ & Atividade profissional & Disciplina & Pesquisa & Designs \\
\hline $\begin{array}{l}\text { Relacionado às } \\
\text { configurações } \\
\text { estéticas do } \\
\text { produto. }\end{array}$ & $\begin{array}{l}\text { O atuante e } \\
\text { profissional do design. }\end{array}$ & $\begin{array}{l}\text { Relacionado ao corpo de } \\
\text { conhecimento, conteúdos } \\
\text { e bases de pesquisa para } \\
\text { o curso de Design. }\end{array}$ & $\begin{array}{l}\text { Investigação } \\
\text { sistemática cujo } \\
\text { objetivo é } \\
\text { conhecimento ou } \\
\text { a materialização } \\
\text { de coisas e } \\
\text { sistemas feitos } \\
\text { pelo homem. }\end{array}$ & $\begin{array}{l}\text { Reflexo da } \\
\text { polissemia e o } \\
\text { caráter } \\
\text { complexo da } \\
\text { palavra design. }\end{array}$ \\
\hline
\end{tabular}


Esse retrato das possibilidades do design está vinculado direta e indiretamente à sua atividade profissional e essa abrangência de classificações vem do seu caráter polissêmico, que abre espaço para a compreensão de um design essencialmente complexo (POSSATTI, LINDEN e SILVA, 2014). A respeito disso, Cardoso (2013) destaca que a complexidade existente no campo do design não deve ser combatida, de modo contrário, ela deve ser aceita como condição para soluções projetuais.

Ressalta-se, assim, que o termo "design" está envolto de uma ampla abrangência de significações, devido às suas características peculiares, como a pluralidade, complexidade e polissemia. Acima disso, ainda está passível de interpretações parciais pelas mídias publicitárias, que o expõe para a população relacionando-o comumente às propriedades estéticas, a qual Possatti, Linden e Silva (2014) destacam ser apenas uma entre as várias concepções do termo "design". No cenário brasileiro estes fatores se agravam diante a sua recente implementação, a ausência de uma regularização do curso e a mudança recente em sua nomenclatura.

Dessa forma, nota-se que há múltiplos elementos que se apresentam como possíveis dificuldades para a interpretação (do significado) do termo "design", provindas desde a sua origem e concepção pluralista até a implementação do campo no espaço brasileiro. Diante a essas interferências, propõe-se analisar a interpretação do significado do termo pela população em face de sua aplicação em produtos e serviços.

\section{MÉTODOS E TÉCNICAS}

A presente pesquisa possui natureza básica, com abordagem qualitativa e possuindo objetivo descritivo, a partir do qual foi aplicado um questionário (SILVA; MENEZES, 2005).

Para o estudo aplicou-se um questionário de forma virtual, como a possibilidade de um maior número de respondentes, ter uma maior abrangência em termos de área de atuação e diversidade geográfica, além de sua eficiência e baixo custo de aplicação (IIDA \& GUIMARÃES, 2016; MOREIRA, 2016). A aplicação deste questionário teve como principal intuito a interpretação (quanto ao significado) e a percepção que os respondentes possuíam a respeito do conceito de design e de sua área profissional.

Em relação à amostra, o critério de seleção consistiu na seleção de pessoas relacionadas com o ensino, com a academia e com o mercado, além de indivíduos fora do meio do design a fim de confrontar as opiniões e fomentar a discussão. Assim subdividiram-se os indivíduos em três grupos diferentes: pessoas de outras áreas profissionais, que não possuem qualquer relação com o conhecimento acadêmico ou profissional com a área do design; os designers, indivíduos já graduados e com experiências na área; e os estudantes da área de design, que estão atualmente na academia ou em cursos técnicos adquirindo conhecimento sobre o campo.

A intenção em aplicar o questionário nesses perfis consiste em explorar as diferentes concepções do design de acordo com o conhecimento desses indivíduos, sejam eles de outras áreas, ou alunos em estado de aprendizado ou profissionais que já atuam como designers. Ao todo se registraram 82 respondentes. 
O questionário compreendeu duas seções: a primeira dispôs de quatro perguntas de quesito social para elaboração de perfil: idade, gênero, escolaridade e profissão. Na segunda etapa, foram explorados e aprofundados os aspectos de interpretação do design através de oito perguntas: a) Como os respondentes conceituam o design ou como o definem; b) O que esperam de um empreendimento com o termo aplicado; c) Através de que meios (sociais, tecnológicos, acadêmicos, etc.) conheceram o design; d) Como os respondentes veem o termo "design" aplicado em produtos e serviços; e) Quais produtos ou serviços esperam de um empreendimento com o termo design aplicado em seu título; f) O que pensam sobre os denominados autodidatas; g) Se já utilizaram o termo para se promover; e h) Se acreditam em alguma forma de apropriação cultural maranhense para a utilização do termo "design".

Ressalta-se que a coleta de dados foi realizada somente no estado do Maranhão, com o intuito de entender, especificamente, a interpretação (pelo significado) do termo em questão por parte da população deste estado onde há, atualmente, duas Universidades (pública e privada) com cursos de graduação em design, também são oferecidos dois cursos técnicos na área de design, uma por uma Instituição Pública Federal, outra pelo Serviço Nacional de Aprendizagem Industrial (SENAI).

Para embasar os resultados dos questionários, realizou-se um registro fotográfico da aplicação do termo "design" em produtos e serviços no mesmo cenário local. Ao todo, obtiveramse 54 fotos, provenientes de mídias como: panfletos, outdoors, banners, cartazes, cartões de visitas e placas. Posteriormente, os resultados apurados deste levantamento foram comparados com as resoluções obtidas nos questionários aplicados, a fim de fomentar as discussões com relação ao significado da palavra "design" entre a sua interpretação pela população e as suas aplicações em produtos e serviços.

\subsection{Análise de dados}

Com base nos resultados obtidos, sistematizaram-se os dados em Planilha Microsoft Excel (2010), para organização dos resultados e criação dos gráficos por frequência de respostas. Quanto aos respondentes, $52 \%$ foram de pessoas sem experiência e conhecimento técnico na área do design ou agentes externos dessa área, enquanto, 32\% foram de estudantes da área de design, enquanto, por último, $16 \%$ foram professores e profissionais da área de design (Figura 1). Os resultados foram analisados tanto em sua total abrangência, como também foi feita a estratificação de cada um desses grupos com a intenção de observar os resultados específicos de cada grupo. Posteriormente, esses mesmos resultados foram avaliados em um quadro comparativo com os demais grupos, a fim de visualizar suas semelhanças e divergências. 
Figura 1: Categorização e percentual dos grupos participantes da pesquisa.

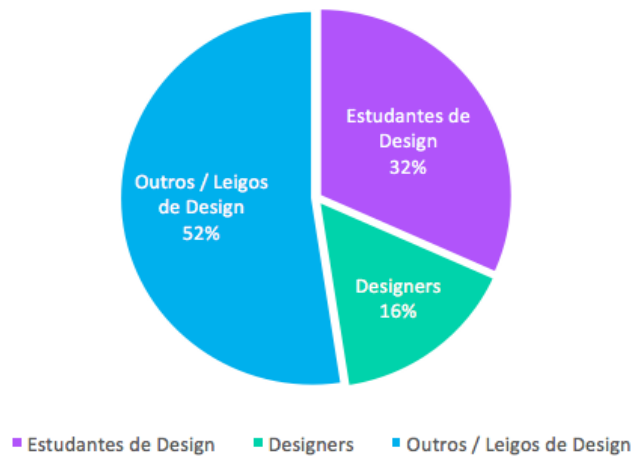

Fonte: os autores.

\section{RESULTADOS E DISCUSSÕES}

\subsection{Seção 1 - Perfil dos respondentes}

A construção do perfil indicou que $54 \%$ dos respondentes são do gênero feminino, enquanto que $46 \%$ são do gênero masculino. Com relação a idade dos mesmos, $68 \%$ tinham entre "18 a 25 anos", enquanto $16 \%$ eram relativos ao grupo de "26 a 35 anos", seguidos pelo agrupamento de pessoas entre "36 a 45 anos" com 13\%, e por fim, o grupo de "46 a 55 anos", com 3\% (Figura 2).

Figura 2: Gráfico gerado para o índice de idade dos participantes do questionário.

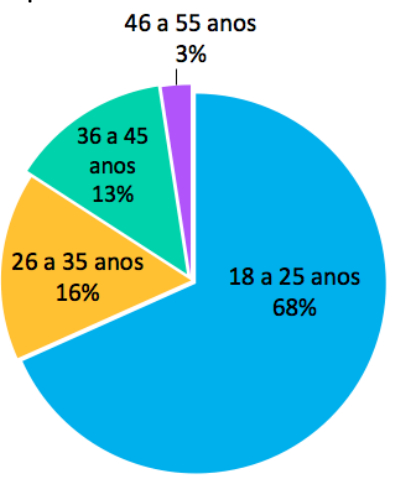

Fonte: os autores.

A respeito da escolaridade dos indivíduos participantes, a maioria coincidiu com a parcela representativa dos estudantes de design, pois em primeiro surge o grupo de "ensino superior incompleto" que lidera em participação com índice de 55\% dos respondentes, seguido por $21 \%$ daqueles com o "ensino superior completo", envolvendo tanto os indivíduos externos ao design, como também profissionais formados na área. Em terceiro, com 15\%, aparecem os respondentes enquadrados no grupo de "pós-graduação completa", e por último grupo encontram-se os de "pós-graduação incompleta" (Figura 3). Os grupos de indivíduos com pós-graduação, tanto completa quanto incompleta, abarcam profissionais de formações diversas, estando vinculados ao design ou não. 
Figura 3: Gráfico gerado para o índice de escolaridade dos participantes do questionário.

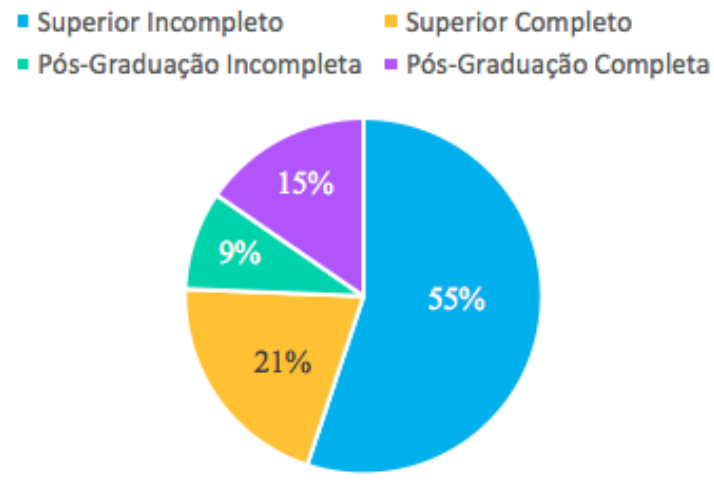

Fonte: os autores.

\subsection{Seção 2-Questionamentos}

Como apresentado na Figura 4, os questionários apontam que, entre as principais atribuições, design é conceituado por 27 indivíduos como "projeto", enquanto 18 relacionam o design com "criação ou criatividade", seguido por "resolução de problemas" com 15 respostas e "desenvolvimento de produtos ou serviços", que aparece em quarto lugar, com 11. Para Fascioni (2014) o trabalho do designer é essencialmente de projeto, o que vai ao encontro com os resultados apurados. Contudo, ao isolar os resultados dos grupos participantes, observa-se que entre os estudantes da área de design, 65,3\% apontaram design como "projeto", enquanto que não possuem conhecimento acadêmica da área alcançaram o índice de 18,6\% para o mesmo resultado, consideravelmente menor comparado aos estudantes de design. Observa-se que parte desse resultado é da lógica consequência do contato mais frequentes desses estudantes com o conglomerado do design e pela fundamentação teórica adquirida durante a formação, enquanto que os agentes externos da área do design o assimilam de maneira superficial e externa.

Por outro lado, apenas 15,3\% dos profissionais da área de design apontaram "projeto" como parte de suas respostas. O maior consenso para essa categoria foi dedicada à "resolução de problemas" e "desenvolvimento de produtos ou serviços", com respectivos 30,7\% dos resultados. Conclui-se que para estes designers, o projeto não é o conceito mais determinante para a área. Para eles, a atribuição "resolução e solução de problemas ou necessidades" e "desenvolvimento de produtos ou serviços" são mais apropriadas para o design.

Entre outras principais atribuições levantadas para conceituar e definir o design, estas foram distribuídas, de modo geral, entre: "metodologia e processo" (8), "forma" (8), "funcionalidade" (6), "desenho" (6) e "inovação e diferencial" (6). 
Figura 4: Frequência de respostas dadas como conceito de design.

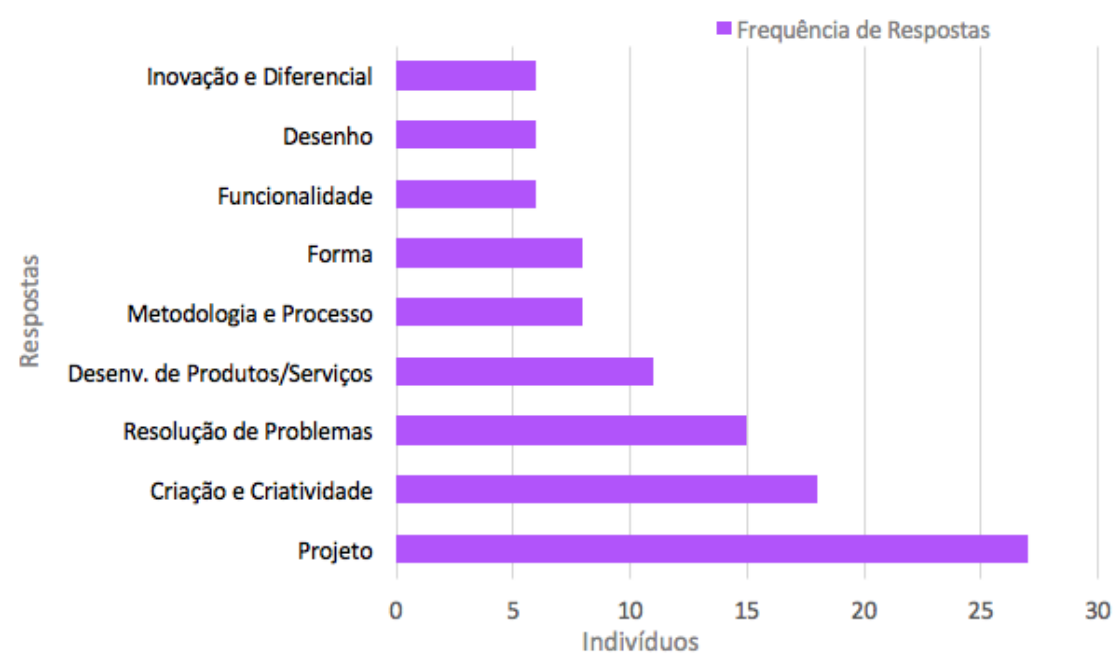

Fonte: os autores.

Entre as principais fontes que contribuíram para a formação do conceito de design, a "internet" é a mais conotada, com 46 respostas, tornando-se, assim, a principal contribuidora das definições atribuídas ao design pelos respondentes (Figura 5). Com relação a este dado, Landim (2008) e Bonsiepe (2012), apontam que nas últimas décadas as mídias em massas tornaram-se fortes influenciadores na proliferação do design na sociedade. Assim, observa-se que as novas tecnologias midiáticas, como a internet e os seus influentes canais de comunicação, são grandes responsáveis pela disseminação e compreensão popular do design, e que os resultados desse levantamento vão ao encontro com o que é afirmado pelos autores.

Além da internet, outras principais fontes que contribuíram para a formação do conceito de design são a "formação acadêmica" indicada por estudantes e profissionais da área, com 29 respostas obtidas, a influência de "amigos", obtendo 28, e os livros, com 21 . Outros colaboradores, com resultados inferiores, são as "revistas" (15), "experiências com a área" (7) e a "literatura científica" (6), tendo como exemplos, artigos, teses e monografias. 
Figura 5: Frequência de respostas sobre fonte de informações que contribuíram para a formação do conceito de design.

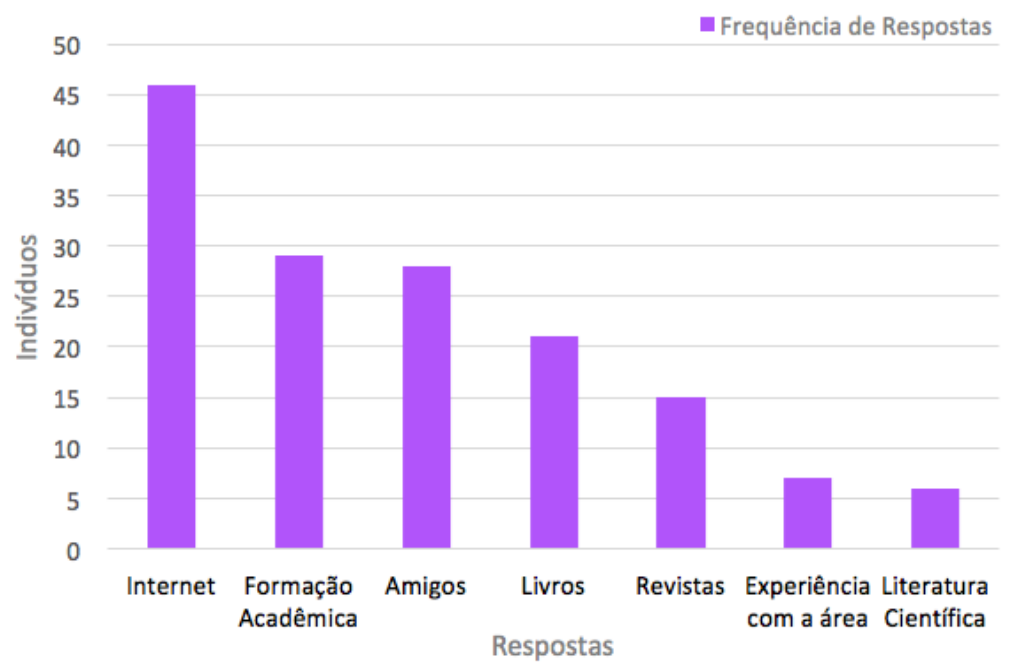

Fonte: os autores.

De acordo com os dados da Figura 6, os produtos e serviços mais esperados pelos consumidores, ao deparar-se com o emprego do termo design em empreendimentos, são "móveis", que recebeu ao todo 17 indicações. Em seguida, com 14 das respostas atribuídas, temse a categoria de "peças e serviços gráficos", seguida pelas categorias, "projetos", com 12, além de "produtos diferenciados e inovadores" e "resolução de problemas", obtendo 8 para cada. "Design de interiores", "moda" e "qualidade" aparecem logo após com 6 indicações.

Figura 6: Frequência de respostas acerca de produtos ou serviços esperados de um empreendimento que apresenta a palavra "design" no seu título/marca.

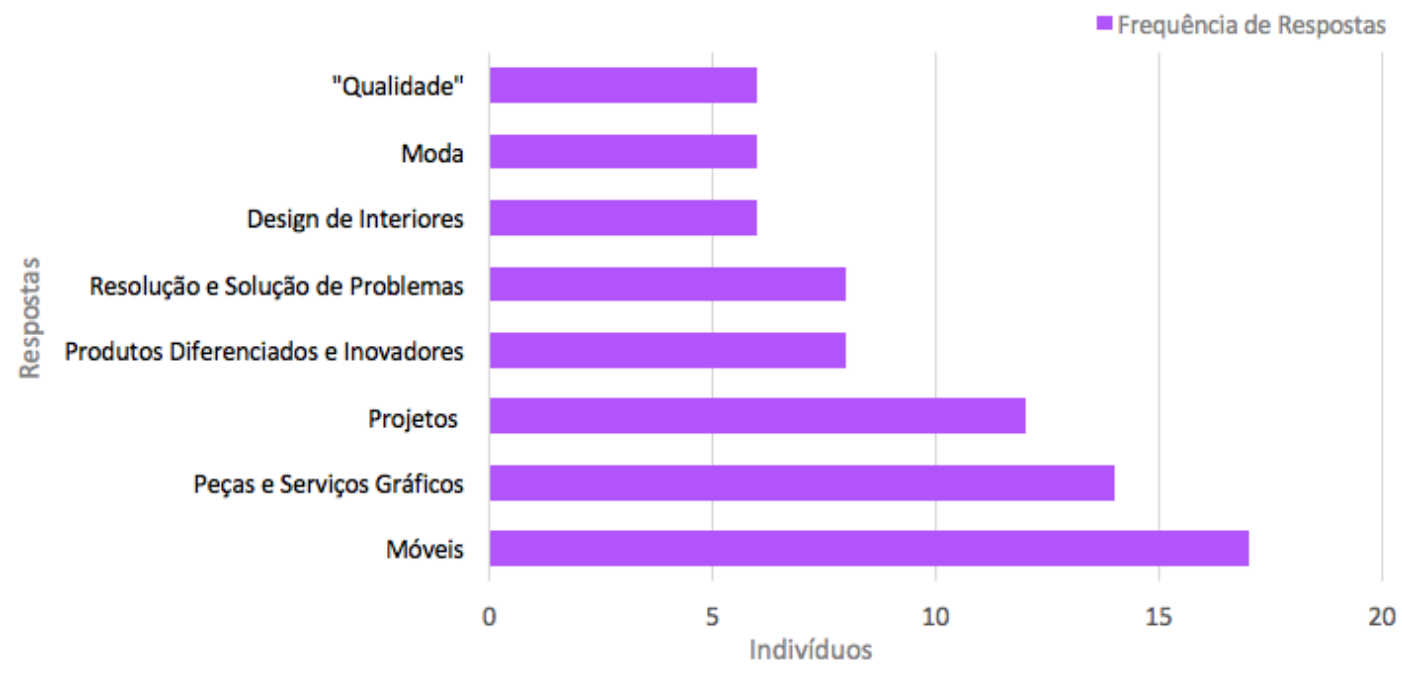

Fonte: os autores.

Sobre a utilização da palavra design para promoção de bens e serviços, $74,4 \%$ dos entrevistados presenciaram a utilização do termo design em produtos e serviços. Os relatos apontam que a palavra é amplamente vista em segmentos comerciais em áreas não projetuais, 
pois das 58 respostas desse enunciado, apenas 11 indicam o design para o segmento projetual (especificamente quatro para design de interiores e sete para design gráfico), alcançando o baixo índice de $18,9 \%$. Os resultados se equiparam ao levantamento fotográfico, que ratifica a extensa utilização do termo em oficinas mecânicas, salões de belezas e demais serviços estéticos, como pode ser visualizado nos exemplos da Figura 7.

Figura 7: Exemplos da disseminação do termo design apropriado em produtos e serviços.

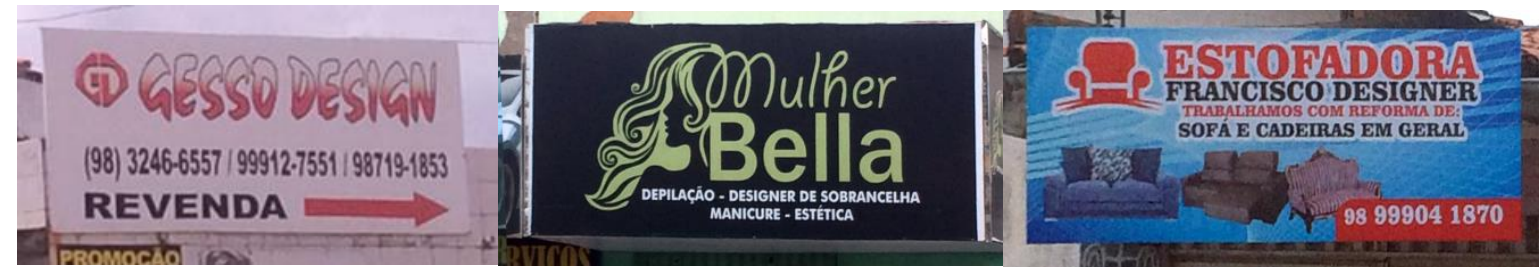

Fonte: os autores.

Além disso, Niemeyer (1997) apud Moura (2003) apontam que a falta da particularização do design, quanto a profissão e conceito, gera o emprego equivocado da palavra para qualquer atividade profissional que faça algum tipo de modificação formal ou gráfica, como, por exemplo, os mais relatados no gráfico da Figura 8. Nota-se que em serviços voltados para a beleza têm-se o emprego comum da palavra, sendo o "design de sobrancelhas" o mais encontrado, obtendo 25 respostas. Além dele, observa-se a vasta utilização do termo design nos próprios salões de belezas ou, de modo geral, empreendimentos de serviços estéticos, possuindo 16 relatos, que é seguido pelas "confeitarias" ou "design de bolos", com 12, confirmando pelos resultados do mapeamento sobre a aplicação do termo "design" em instituições comerciais, que também apontaram ampla utilização do termo por estabelecimento comerciais estéticos. Posteriormente, têm-se "móveis" e "design gráfico" com 10 e 7 indicações, respectivamente.

Figura 8: Frequência de situações presenciadas diante a utilização da palavra design para promover produtos e serviços.

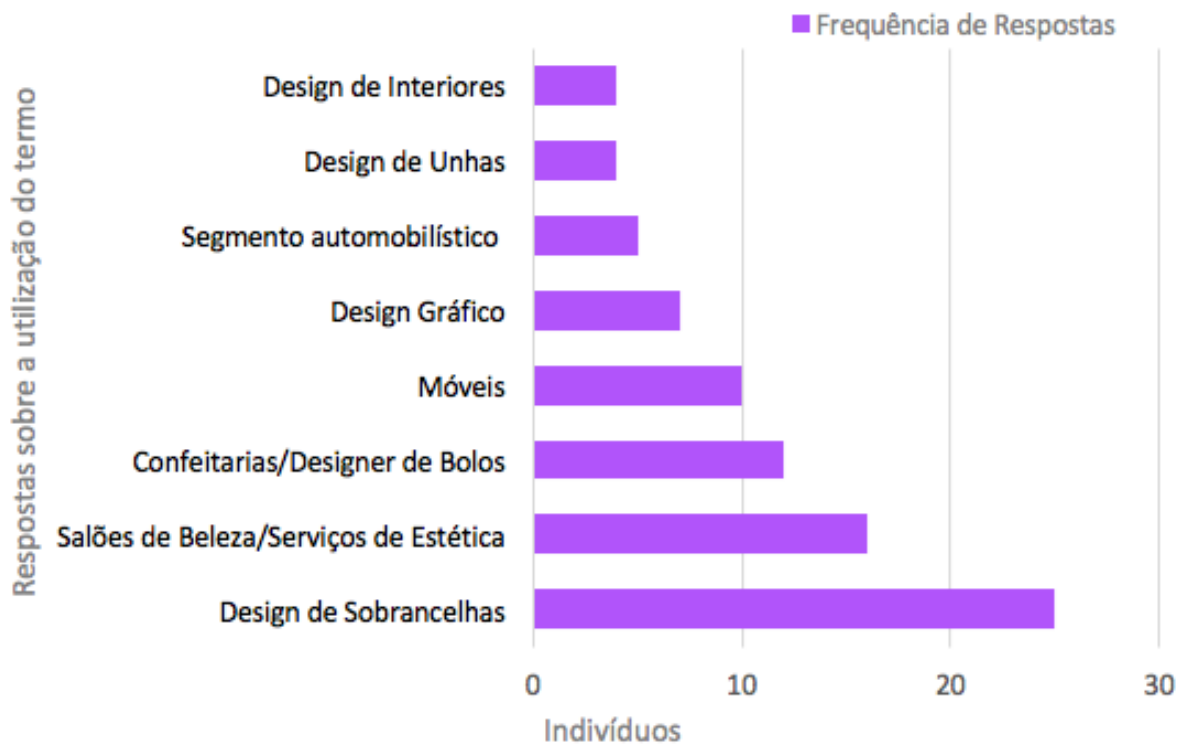

Fonte: os autores. 
Outro fator analisado foi relativo a utilização da palavra design como indicador de buscas por novos produtos, sendo que $43,9 \%$ dos entrevistados usam o termo com o intuito de obter resultados acerca de produtos e serviços. E apesar das respostas terem sido bem divergentes, os segmentos "automobilísticos", "moveleiros", "produtos diferenciados e inovadores" e "serviços gráficos" se destacaram entre os demais. Dessa forma, nota-se que o público relaciona continuamente design às atividades comerciais moveleiras, principalmente quando se referem a móveis projetados, além do setor automobilístico, abrangendo desde concessionárias até oficinas de manutenção e troca de peças. Acima disso, vinculam o design a produtos diferenciados e inovadores, servindo como um valor de garantia de qualidade e acabamento, além da vinculação aos diversos segmentos do design gráfico como branding, naming e a criação de logos.

Observou-se que $76,8 \%$ dos indivíduos não consideram os profissionais com capacitação técnica em outras áreas como "design de sobrancelha", "hair design" e "cake design" como profissionais de design, alegando que a graduação é necessária para o aprendizado e atuação do designer, e que o contato com a universidade proporciona o conhecimento necessário de fundamentação dos processos projetuais. Por outro lado, 23,2\% consideram que a capacitação técnica também fornece conhecimento relacionado a área, mesmo que de uma forma mais restrita e focada apenas no conhecimento prático e na habilidade de ferramentas. Sobre o aspecto dos "autodidatas", Fascioni (2014) defende que qualquer pessoa pode sentir-se à vontade e sem inibição para interferir e mudar completamente os projetos gráficos ou de produtos, sem possuir nenhum conhecimento dos processos de criação, atitude esta que não se presencia em áreas como medicina, arquitetura e engenharia civil.

Contudo, ainda para Fascioni (2014), este fenômeno não deve ser avaliado com a finalidade de denegrir os "autodidatas", mesmo que eles não sejam validados como "designers" em sua concepção, pois os seus conhecimentos são limitados e específicos às ferramentas técnicas, como os respondentes aos seus favores indicaram. Porém, a atuação do designer excede esses limites e abrange um extenso corpo de conhecimento voltado ao segmento projetual, que é um dos principais fatores que os capacitam como um profissional de "designer". Ainda assim, apesar dessas diferenças, tanto os "autodidatas" como os designers são capazes, em determinados casos, de exercer os seus papéis de modo complementar para alcançarem certos objetivos. Assim como os arquitetos e os pedreiros o fazem em, por exemplo, construção de casas, ou seja, o fundamental é compreender que ambos exercem papéis diferentes, ressaltando a lógica de que o ensino para os "designers" que passam pela academia é mais completo e dotado de maior garantia à prática projetual, enquanto os "autodidatas" são limitados ao domínio de programas e conhecimento prático e são direcionados à solução de demandas mais simples e específicas.

Dos indivíduos entrevistados, $60 \%$ não acreditam no design genuinamente maranhense, enquanto $16 \%$ consideram que sim (Figura 9). Esse percentual bem mais expressivo da desconsideração do design local se apresenta como uma deficiência na percepção do design e seu potencial, o que se agrava quando se analisa que a capital do Maranhão, São Luís, é considerada um pólo cultural que pode se beneficiar com o design por meio do processo de valorização de seu capital identitário, produtos e saberes ao promover as origens de seus recursos, impactando na comunidade e na economia local (OLIVEIRA, MARQUES E GUEDES, 2016; SOUZA, KRUCKEN E ALMENDRA, 2016). Portanto esse pensamento leva ao desperdício de potencial que poderia ser desenvolvido com o design, podendo ser relacionado com é apresentado por Moreira (2016), 
onde afirma que a falta de conhecimento sobre a área esteja relacionada com a subutilização das práticas do designer.

Para os que responderam em benefício do design maranhense, as principais alegações são vinculadas a própria cultura local, como a arquitetura e o design interiores, utilizado, então, como referência na elaboração de projetos. Apontam também para a ampla utilização do termo em setores comerciais populares do Estado para a agregação de valores em seus produtos e serviços.

Figura 9: Índice dos indivíduos que acreditam ou não no design genuinamente maranhense.

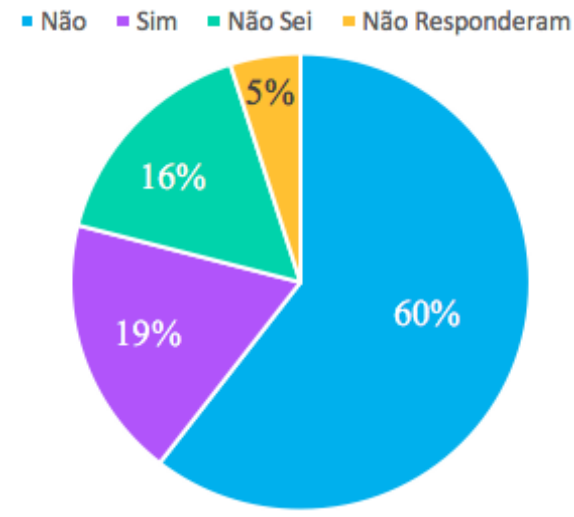

Fonte: os autores.

\section{CONSIDERAÇÕES FINAIS}

Como visto, o design carece de conceitos concretos ou bem delimitados. Ele contém um caráter mutável, que se molda frente à sociedade, a qual se apropria dessa faceta do design empregando-o conforme as suas ambições. Através dos resultados obtidos, constatou-se que o uso do termo design está amplamente associado com a estética, assim como a uma forma de agregar valor nas atividades comerciais, seja na denominação de empreendimentos, ou na utilização como um "adjetivo" de qualidade em seus serviços, sem contar com a sua utilização para promover outras áreas comerciais, tais como design de sobrancelhas, bolos e convites. Desta maneira, o design é visto como uma vantagem competitiva no comércio, porém essa percepção não se dá na forma que deveria, de modo a entender que o design gere essa vantagem competitiva, ele deve englobar todo o processo de planejamento e produção desses bens e serviços, não apenas em uma esfera superficial ou com a aplicação de etapas segmentadas (MOREIRA, 2016).

De acordo com Moreira (2016, p. 68 -69):

[...] o Design marca presença na maioria das empresas. No entanto, muitas vezes, verificou-se que esse ocorre de forma pouco significativa sob o ponto de vista da estratégia. Nesse sentido, se antes o desafio era colocar o Design nas corporações, hoje, parece que a necessidade é expandi-lo em um âmbito mais intangível e estratégico. Para tanto, é possível relacionar que a falta de conhecimento sobre a área esteja relacionada com a subutilização das práticas do designer e com o pouco espaço que essas possuem em muitas empresas. 
Como dito, essa impressão é consequência de sua grande exposição na mídia nos últimos anos e, portanto, o seu entendimento continua impreciso para grande parte do público. $\mathrm{Na}$ presente pesquisa, das 58 situações relatadas pelos entrevistados diante a utilização do termo, apenas 11 (18,9\%) delas estavam voltadas a design como projeto, evidenciando o seu emprego para gerar valor e desejabilidade em outros segmentos comerciais.

Com os resultados apontados, os meios de comunicação, sobretudo e principalmente a internet, possuem forte impacto como propagadores de conhecimento acerca da área. Mas com os empecilhos apresentados, como a ausência de um consenso na discussão constante a respeito do conceito de design, a interdisciplinaridade que o conecta com outras áreas de conhecimento que interferem nas suas delimitações, assim como as brechas geradas pela falta da regulamentação, geram questionamentos sobre: como se chegar a um consenso completo do conceito de design junto à sociedade? Como desvincular o design das situações apresentadas, sendo que estas englobam a realidade brasileira? Landim (2010, p. 131) explana:

A compreensão do design brasileiro é dificultada pela aquisição de diferentes vertentes, modelos e principalmente do entendimento da realidade do país. Quando analisam-se designers como os Campana e Guto Índio da Costa, por exemplo, é claramente percebido como o Brasil abriga um coquetel de abordagens e definições.

Esse coquetel de abordagens e definições, relatada por Landim (2010), exemplifica e enquadra as perspectivas empregadas ao termo design em produtos e serviços, pois este se desdobra, por exemplo, entre títulos de empreendimentos a serviços estéticos, sendo reconfigurado conforme suas abordagens. E esses desdobramentos acabam por condicionar $e$ rotular os conceitos e atribuições com relação ao design vinculando-o a serviços e produtos. Como visto, o termo é empregado constantemente em "salões de beleza", serviços de "design de sobrancelha", "móveis" e setores "automobilísticos".

Portanto, ainda é essencial averiguar outros aspectos além destes resultados apurados. Dessa forma, para posteriores estudos, pretende-se ir ao encontro dos indivíduos que se apropriam do termo em outros setores comerciais, incluindo os do âmbito informal, buscando compreender e analisar todo este processo de apropriação do termo com maior proximidade e delineação. Além disso, deve-se coletar uma amostra com maior abrangência do nível de escolaridade, visto que na pesquisa atual pontuou-se um alto índice de escolaridade dos participantes. Assim, a averiguação da compreensão do design entre os indivíduos com menores formações deve ser constatada futuramente.

\section{REFERÊNCIAS}

AZEVEDO, W. O que é Design. São Paulo: Ed. Brasiliense, 1998.

BONFIM, G. A. Teoria e Crítica do Design. In: Seminário de Estudos e Pesquisas em Design. Universidade Anhembi Morumbi. São Paulo, 2002.

BOMFIM, G. A. Fundamentos de uma teoria transdisciplinar do design: Morfologia dos objetos de uso e sistemas de comunicação. In: COUTO, R. M. S.; FARBIARZ, J. L.; NOVAES, L (Org.). Gustavo Amarante Bomfim: Uma coletânea. Rio de Janeiro: Rio Book's 1o Edição 2014.

BONSIEPE, G. Design como prática de projeto. São Paulo: Blucher, 2012.

CARDOSO, R. Design para um mundo complexo. São Paulo: Cosac Naify, 2013. 
DINIZ, R. L.; ARRUDA FILHO, M. P.; SILVA ARAÚJO, M. L.; BARROS, R. dos S. Levantamento sobre a aplicação da palavra "Design" em produtos e serviços na cidade de São Luís (MA). In: Congresso Brasileiro de Pesquisa e Desenvolvimento em Design, 12. Anais... São Paulo: Blucher, 2016. v. 9, p. 803-813.

FASCIONI, L. O design do designer. 2. Ed. [S.I.]: Ligia Fascioni, 2014. 172 p. Disponível em: <http://www.ligiafascioni.com.br/wp-content/uploads/2010/08/DesignDesignerLigiaFascioni.pdf>. Acesso em: 21 de maio de 2017.

IIDA, I.; GUIMARÃES, L. B. de M. Ergonomia: projeto e produção. 3. ed. São Paulo: Blucher, 2016.

LANDIM, P. C. Design, empresa, sociedade [online]. São Paulo: Editora UNESP; São Paulo: Cultura Acadêmica, 2010. 191 p. ISBN 978-85-7983-093-8.

LÖBACH, B. Design Industrial: Bases para configuração dos produtos Industriais. São Paulo: Blucher, 2001.

MOREIRA, B. R. Gestão do Design na prática: Framework para implementação em empresas. 2016. 279 f. Tese (Doutorado) - Curso de Programa de Pós-graduação em Design, Escola de Engenharia, Universidade Federal do Rio Grande do Sul, Porto Alegre, 2016.

MOURA, M. C. de. $O$ design de hipermídia. São Paulo: 2003. 357f. Tese (Doutorado) - Programa de Pós-Graduação em Comunicação e Semiótica, Pontifícia Universidade Católica de São Paulo, São Paulo, 2003.

OLIVEIRA, I. C. M.; MARQUES, A. M. D. R.; GUEDES, M. G. P. R. Design social para valorização de uma identidade local - design de sistemas sociais. In: INTERNATIONAL FASHION AND DESIGN CONGRESS, 3. Anais... Braga: Universidade do Minho, 2016.

POSSATTI, G. M.; LINDEN, J. C. de S. V. D.; SILVA, R. P. da. REFLEXÕES SOBRE AS RELAÇÕES ENTRE DESIGN E COMPLEXIDADE. In: Congresso Brasileiro de Pesquisa e Desenvolvimento em Design, 11. Anais. São Paulo: Blucher, 2014. v. 1, n. 4, p. 386-397.

SERVIÇO BRASILEIRO DE APOIO ÀS MICRO E PEQUENAS EMPRESAS - SEBRAE. Design no Brasil: relatório 2014 do setor de design. Brasília: SEBRAE, 2014. 196 p. Disponível em: <http://www.bibliotecas.sebrae.com.br/chronus/ARQUIVOS_CHRONUS/bds/bds.nsf/2ab72b8e79 c2a6e7e2be32d09f0cd4a0/\$File/4961.pdf>. Acesso em: 20 de maio de 2016.

SILVA, E. L. da; MENEZES, E. M. Metodologia da pesquisa e elaboração de dissertação. 4. ed. Florianópolis: UFSC, 2005. 138 p.

SOUZA, A. T. de; KRUCKEN, L.; ALMENDRA, R. A. DESIGN PARA O DESENVOLVIMENTO LOCAL: Uma abordagem baseada nos recursos materiais e construtivos. In: Simpósio Brasileiro de Design Sustentável, 5. Anais... São Paulo: Blucher, 2016. v. 2, n. 5, p. 52-61. 